\title{
DIAKRONIKA
}

Vol. 18 No. 1 Th. 2018 p: 46-53

ISSN: 1411-1764 (Print) | 2620-9446 (Online)

http://diakronika.ppj.unp.ac.id

\section{"Pompai:" Studi Tentang Surat Kabar Anak Masa Kolonial Sumatera Barat}

\author{
Hendra Naldi, Najmi \\ hendranaldi@yahoo.co.id; najmiunp86@gmail.com \\ Universitas Negeri Padang
}

\begin{abstract}
POMPAl is a child newspaper born in colonial times. This newspaper comes along with the emergence of movements in Indonesia. Before becoming a child newspaper, POMPAl was a newspaper that also often voiced national movements. Suspicion and pressure from the colonial government, made POMPAl transformed into a child newspaper with the aim of educating indigenous children, especially in West Sumatra. There are several children's newspapers that appear together with the POMPAI newspaper. Among them; Chain Mas and Pelipoer Heart. Both of these newspapers have similarities and differences but have the same goal of wanting to entertain indigenous children and teach knowledge through newspapers. Not many of these children's newspapers are present in West Sumatra. In addition to the pressure from the colonial government, the economic condition of indigenous newspaper businessmen is often a constraint. Age of this newspaper can be said not long or last long. POMPAl itself only lasted about two years. However, his role in the development of the knowledge of indigenous children is taken into account. This can be seen from the rubric and writing as well as the influence of the newspaper POMPAI. Not many natives children can attend school, this newspaper beceme one means of education for them to be illiterate and learn a little to increase knowledge.
\end{abstract}

Keywords: POMPAl, Newspaper Kids, West Sumatera

\begin{abstract}
Abstrak
POMPAl adalah surat kabar anak yang lahir pada masa kolonial. Surat kabar ini hadir dengan bersamaan dengan munculnya pergerakan di Indonesia. Sebelum menjadi surat kabar anak, POMPAl adalah surat kabar yang juga sering menyuarakan gerakan-gerakan nasional. Kecurigaan dan tekanan dari pemerintah kolonial, membuat POMPAl bertransformasi menjadi surat kabar anak dengan tujuan mencerdaskan anak-anak pribumi khususnya di Sumatera Barat. Ada beberapa surat kabar anak yang terbit bersamaan dengan surat kabar POMPAI. Di antaranya; Rantai Mas dan Pelipoer Hati. Kedua surat kabar ini memiliki persamaan dan perbedaan tetapi memiliki tujuan yang sama yaitu ingin menghibur anak-anak pribumi serta mengajarkan pengetahuan melalui surat kabar. Tidak banyak surat kabar anak ini hadir di Sumatera Barat. Selain karena tekanan dari pihak pemerintah kolonial, kondisi ekonomi dari pengusaha surat kabar pribumi pun sering menjadi kendala. Umur surat kabar ini bisa dikatakan tidak panjang atau bertahan lama. POMPAI sendiri hanya bertahan sekitar dua tahun. Namun, peranannya dalam perkembangan pengetahuan anak pribumi cukup diperhitungkan. Hal ini terlihat dari rubrik dan
\end{abstract}


tulisan serta pengaruh yang ditimbulkan dari surat kabar POMPAl. Tidak banyak anak-anak di kalangan pribumi yang bisa bersekolah, dari surat kabar inilah sebagai salah satu sarana pendidikan bagi mereka untuk bebas dari buta huruf dan sedikit banyak belajar untuk menambah pengetahuan.

Kata Kunci: POMPAl, surat kabar anak, Sumatera Barat

This work is licensed under the Creative Commons Attribution-Share Alike 4.0 International License.

\section{Pendahuluan}

Politik etis yang diterapkan pemerintah kolonial Belanda, memberikan keuntungan tersendiri bagi masyarakat Indonesia. Terutama dalam hal pendidikan. Dari bidang pendidikan ini, masyarakat sudah mulai sadar untuk menulis hingga mendirikan berbagai industri media (pers). Ini ditandai dengan banyaknya media surat kabar dan majalah yang muncul pada awal abad-20. Khusus di Sumatera Barat terdapat puluhan surat kabar yang lahir dan terbit (Naldi, 2002). Munculnya banyak terbitan surat kabar tersebut menandakan masyarakat sudah sadar akan pentingnya informasi dan sadar akan membaca serta menulis.

Surat kabar yang terbit di Sumatera Barat awal abad-20 bervariasi dan beragam. Keberagaman surat kabar yang terbit dilihat dari berbagai macam tema maupun judul dari surat kabar tersebut. Surat kabar dengan tema perempuan pun sudah terbit pada awal abad ke-20, seperti Soenting Melayu (1912-1921) terbit di Padang, dan Soeara Kaoem Iboe Soematera (1925-1930) terbit di Padang Panjang. Surat Kabar dengan tema Islam seperti Al-Munir (1911-1915) terbit di Padang, Al-Itqan (1920-1923) dari Maninjau, dan Perwarta Islam (1923-1925) terbit di Bukittinggi. Surat Kabar dengan tema adat seperti Boedi Tjaniago (1922) terbit di Padang Panjang, dan Barito Minangkabau (1926) dari Bukittinggi (Naldi, 2002). Surat kabar dengan tema anak-anak yaitu, POMPAl (1932) terbit di Padang, Rantai Mas (1931) terbit di Kayu Tanam, Pelipoer Hati (1934) terbit di Bukittinggi (Dewi, 2014).

Dari berbagai macam surat kabar tersebut, akan dikhususkan tentang surat kabar anak yaitu: POMPAI. Surat kabar ini merupakan salah satu surat kabar yang terfokus pada pendidikan anak. POMPAl yang terbit pada tahun 1929, awalnya merupakan surat kabar yang berisikan tentang perekonomian di Indonesia, namun kemudian pada tahun 1932 beralih pada pendidikan anak-anak. POMPAI sendiri merupakan singkatan dari Pemberita Oentoek Memadjoekan Peroesahaan Anak Indonesia. Tokoh yang mempelopori berdirinya POMPAI adalah pengusaha Minang yaitu Sjamsuddin Rassat yang juga seorang guru di sekolah Adabiah Padang (Dewi, 2014). Tujuan awal 
berdirinya POMPAI yaitu bermaksud untuk menyatukan seluruh kekuatan pengusaha Indonesia agar bisa bersaing dengan pengusaha asing.

\section{Metode}

Sebagai sebuah penelitian sejarah, tentunya penelitian ini memakai metode sejarah pada umumnya. Mulai dari pengumpulan sumber yang memakai studi kepustakaan. Berdasarkan topik yang diteliti, penelitian ini berbicara mengenai surat kabar masa kolonial, tentunya sumber-sumber tersebut dominan didapatkan di Perpustakaan Nasional Jakarta dan Pusat Dokumentasi dan Informasi Kebudayaan Padang Panjang. Selain itu arsiparsip yang didapatkan dari Arsip Nasional Republik Indonesia (ANRI) Jakarta, yang dibutuhkan terutama dalam melihat kebijakan pemerintah kolonial Belanda terhadap media pers yang terbit pada masa-masa itu.

Sumber-sumber berupa surat kabar sezaman dan arsip tersebut merupakan sumber primer pada penelitian ini. Sumber pendukung (sumber sekunder) juga bisa dipakai dalam penelitian ini yaitu memakai buku-buku penunjang serta artikel maupun jurnal yang relevan dalam penelitian ini.

Lazimnya studi sejarah, analisa data/sumber juga sangat diperlukan melalui kritik sumber. Kritik sumber ini memakai dua kategori yaitu kritik eksteren dan kritik interen. Tentunya kedua kritik ini sangat diperlukan dalam penelitian ini, karena sumber yang didapat berupa kertas-kertas koran dan kertas-kertas arsip dari masa kolonial. Perlu dianalisa keaslian dan keabsahan isi dari sumber-sumber yang dikumpulkan. Setelah itu sumber-sumber yang sudah dianalisa, disusun menjadi uraian fakta yang akan disentesis melalui analisa logis melalui interpretasi. Hasilnya akan dideskripsikan dalam bentuk penyajian sejarah yaitu berupa penulisan sejarah (historiografi).

\section{Pembahasan}

Sebelum tahun 1930, surat kabar anak-anak di Sumatera Barat belum terlihat dengan jelas perkembangan maupun pertumbuhannya. Hal ini disebabkan oleh masih tingginya angka buta huruf pada masyarakat Sumatera Barat pada masa itu. Hal ini juga terjadi pada surat kabar lainnya di Sumatera Barat (Dewi, 2014). Selain karena beberapa hambatan yang membuat terhambatnya pertumbuhan media pers di Sumatera Barat kondisi pendidikan serta tekanan dari pemerintah Hindia Belanda membuat perkembangan media tidak seperti yang dibayangkan pada masa reformasi hari ini.

Salah satu tokoh yang sangat berperan dalam media pers anak yaitu Mohammad Syafei. Beliau bisa dikatakan sebagai pelopor surat kabar anak di Sumatera Barat. Selain itu, beliau juga sebagai pendiri sekolah yang terkenal 
pada masa kolonial yaitu INS Kayu Tanam atau Indonesisch Nederlandsche School (Ruang Pendidik INS). INS adalah suatu lembaga pendidikan menengah swasta yang bercorak khusus dan berdiri pada 31 Oktober 1926. Sekolah ini mengarahkan pendidikannya tidak hanya melalui teori tetapi juga praktek. Hasil dari praktek atau keterampilan dari murid-murid yang diasuhnya di sekolah tersebut, kemudian dipublikasikan melalui media pers yaitu surat kabar anak. Maka munculnya ide untuk membuat media pers sendiri oleh Mohammad Sjafei dan diberi nama dengan surat kabar anak Rantai Mas (Dewi, 2014).

Rantai Mas merupakan surat kabar anak yang pertama kali terbit di Sumatera Barat. Surat kabar ini terbit pertama kali pada tanggal 1 Januari 1931 di Kayu Tanam dan diterbitkan oleh murid-murid INS Kayu Tanam. Surat kabar ini diterbitkan setiap tanggal 1 dan terbit satu kali dalam sebulan dengan biaya langganan sebesar 1,50 Gulden selama setahun atau 0,25 Gulden selama setengah tahun. Surat kabar ini dipimpin oleh Marah Sutan dan Mohammad Sjafei. Tujuan didirikan surat kabar ini yaitu untuk menunjang pendidikan anak pada masa itu. Mohammad Sjafei sebagai pendiri surat kabar Rantai Mas juga sekaligus sebagai tokoh pendidikan yang sangat berpengaruh pada masa pergerakan. la mengabdikan hidup untuk menemukan formula pendidikan yang tepat untuk membebaskan Indonesia dari penjajahan kolonial. Kondisi masyarakat yang banyak buta huruf dan tidak bisa tulis baca, menggerakkan beliau untuk perlu mendirikan sebuah lembaga pendidikan dan didukung oleh media lokal yaitu surat kabar. Berbekal pendidikan yang diperolehnya dari negeri Belanda, akhirnya beliau berhasil mendirikan sekolah INS Kayu Tanam (Dewi, 2014).

Rubrik-rubrik yang diterbitkan oleh Rantai Mas, pada awalnya rata-rata berisi tentang kreatifitas dan keterampilan para murid-murid dari INS. Hal ini terlihat pada isi dari surat kabar tersebut yang dibumbui dengan gambargambar hasil karya murid dari INS. Selain itu, berbagai tulisan seperti artikel juga sudah dimuat di dalam surat kabar Rantai Mas, seperti artikel yang berjudul “Kesehatan" dan "Gunanya Pengetahuan" (Surat Kabar Rantai Emas, 1931). Artikel ini mengajak pembaca bahwa perlunya menjaga kesehatan dan menjaga makanan. Dalam arti, pola hidup sehat sudah dimulai pada masa tersebut. Hal ini terlihat dari kalimat-kalimat artikel tersebut yang berbunyi;

"Diantara sekalian toekang dajoeng perahoe dalam doenia, boleh dikatakan toekang-toekang dayoeng bangsa Toerki yang mandjadi djagonya, karena sekalian mereka itoe badannja sehat, koeat lagi tangkas, dan rajin. Selama mereka mendjalankan pekerdjaannja, mereka tjoema minoem air tawar saja. Djarang sekali terdapat jang minoem air bertjampoer sari boeah-boeahan 
oempamanja: air bertjampoer air djeroek dan goela - air bertjampoer sirop - air bertjampoer goela dan halia (djahe) dan lain-lain. Dan kalau moesim panas, mereka minoem lebih banjak. Makanannya jang teroetama, jalah roti. Kadang-kadang ditjampoer dengan mentimoen, sedikit daoen-daoen sebagai oelam, dan kadang-kadang sedikit ikan."

Dari potongan artikel di atas, terlihat surat kabar Rantai Mas juga mementingkan bagaimana cara hidup sehat bagi anak-anak dan orang dewasa. Mereka menceritakan bangsa Turki yang hanya minum air putih dan makanan wajibnya adalah roti bisa sangat kuat dan tangkas. Beda dengan di Indonesia yang mencampurkan air dengan gula, sirup maupun jahe masih belum setangkas bangsa Turki.

Selain artikel yang berjudul "Kesehatan”, artikel yang berjudul "Gunanya Pengetahuan" dalam surat kabar Rantai Mas juga sangat mendidik bagi anakanak maupun dewasa. Adapun penggalan artikel tersebut berbunyi:

"Kata orang pandai-pandai; Adapoen pengetahoean itoe boeat koesa - Pikiran jang sesat - kekebalan tingkah lakoe jang tiada senonoh - was-was - agak-agak atau angabn-angan jang boekan-boekan, telah timboel dalam hati manoesia jang tak ada pengetahoean. Sifat bodoh (ta' ada pengetahoean), besar sekali tjelakanya bagi manoesia. Karena kebodohan itoelah jang menjesatkan manoesia. Sebab itu ta' baik sekali-kali njawa seseorang dibiarkan sadja dengan tiada berpengetahoean. Itoelah sebabnja maka akal manoesia itoe perloe sekali ditambah dengan pengetahoean, makin sehari makin besar - Sebab soedah didjadikan Toehan serwa sekalian alam, bahwa akal manoesia itoe dapat bertambah-tambah, koeasa memikirkan, menimbang, mendoega, membanding dan menjelidiki segala rahasia apa joega, baik lahir atau batin. Akan tetapi kalau akal itoe dibiarkan sadja dari ketjil sampai toea, nistjaja akan toempoelah dia, dan tiada dapat bertambah-tambah koeasa, melainkan ta"loeklah ia kepada segala pekerdjaan salah dan sesat."

Pentingnya pengetahuan sangat ditekankan oleh artikel dalam surat kabar Rantai Mas tersebut. Terlihat bahwa dari pengetahuan masyarakat akan cerdas dan tidak dibodoh-bodohi oleh apalagi oleh pemerintah kolonial. Perlunya pengetahuan membuat manusia menjadi lebih berakal sehat dan menimbulkan rasa ingin tahu yang lebih tinggi lagi terhadap pengetahuan tersebut. Jelas bahwa informasi dalam surat kabar Rantai Mas ini menceritakan tentang perlunya pendidikan dan mendapatkan pengetahuan. 
Jadi, peran media pada masa ini sangat besar dalam hal menambah pengetahuan anak dan masyarakat pada umumnya.

Dalam rubrik yang dikeluarkan oleh Rantai Mas juga berisi mata pelajaran Bahasa seperti Bahasa Indonesia, Bahasa Belanda dan Bahasa Inggris. Di sana diajarkan beberapa kosa kata dan makna dari kata maupun kalimat dari berbagai bahasa. Tidak hanya dari sekolah, dari surat kabar Rantai Mas ini, anak-anak mendapatkan pengetahuan yang lebih lagi di luar pendidikan formal yaitu sekolah. Selain pelajaran bahasa juga ada pelajaran akhlak yaitu artikel yang berjudul "Boedi", yang berisi tentang pelajaran budi pekerti serta perilaku sebagai makhluk Tuhan (Surat Kabar Rantai Emas, 1931).

Selain Rantai Mas juga terdapat surat kabar anak yang diberi nama Pelipoer Hati. Surat kabar ini diterbitkan oleh Toko Equator For De Kock (sekarang Kota Bukittinggi) oleh beberapa pemuda yang menyebut diri mereka dengan panggilan "Abang” (Dewi, 2014). Surat kabar ini diterbitkan selain dengan tujuan pendidikan tetapi juga memberikan hiburan pada anakanak. Berbeda dengan Rantai Mas dan POMPAI, Pelipoer Hati lebih banyak mengandung unsur hiburan, namun lewat hiburan yang disajikannya terdapat unsur pendidikan. Seperti rubrik-rubriknya yang banyak menyajikan ceritacerita lucu yang juga mendidik pembacanya untuk menarik kesimpulan dari cerita yang sudah disajikan dan dijadikan pelajaran dalam kehidupan seharihari. Misalnya, rubrik cerita Kancil yang selalu diidentikkan dengan binatang yang cerdik. Di sini memberikan cerita hiburan untuk anak-anak dan juga mendidik bagaimana menjadi cerdik dalam arti yang positif.

Selain cerita, juga terdapat artikel tentang kebersihan dan kesehatan. Seperti penggalan artikel dalam rubrik tersebut yang berbunyi; (Pelipoer Hati, Edisi No. 1, 1934).

"Apabila kau tidak membersihkan tangan dan koekoemoe nistjajalah bibit penyakit itoe selaloe berada padamoe. 1 . Mentjoetji tangan setelah bekerdja dan sebeloem makan, itoelah soeatoe pekerdjaan yang baik benar oentoek pendjagaan kesehatan. 2. Seorang ahli mengatakan bahwa tiaptiap sesoeap nasi haroes dikoenjah 24 kali. 3. Pekerdjaan jang pertjoema benar ialah mandi dengan air jang kotor. Badan ta' bertambah bersih, dan kerap kali mendapat penjakit."

Dari penggalan artikel ini, juga terdapat nilai edukasi bagi anak-anak yaitu pentingnya menjaga kebersihan dan kesehatan. Selain itu mengajarkan bagaimana cara hidup bersih yaitu tidak mandi dengan air kotor dan bagaimana cara makan yang baik agar mudah dicerna oleh usus. Selain artikel di atas, juga terdapat rubrik mengenai pengetahuan umum dan pengetahuan 
dalam kehidupan sehari-hari, seperti pada rubrik berikut; (Pelipoer Hati, Edisi No. 1, 1934).

"Tahoekah adik, bahasa: 1. Oesoes manoesia itoe pandjangnja kira-kira 7 meter. 2. Poelau Djawa 4x, Soematra 13x, Borneo $22 x$, Selebes 5,5x sebesar keradjaan Belanda. 3. Minjak tanah jang sedang menjala tidak dapat dipadami dengan air, melainkan dengan kain basah atau pasir. 4. Semperong lampoe tidak moedah petjah, apabila ia lebih dahoeloe beberapa lamanya direndam dalam minjak tanah. 5. Tidak baik oentoek kesehatan kita apabila malam hari dibiarkan lampoe menjala dalam bilik kita tidoer."

Seperti Rantai Mas, Pelipoer Hati juga terbit setiap bulannya dan pembaca yang ingin berlangganan tiap tahunnya dikenakan biaya 0,75 Gulden. Pelipoer Hati termasuk surat kabar yang sudah mengepakkan sayapnya hingga ke luar negeri yaitu sampai ke Malaysia dan Singapura. Bisa jadi karena hal ini membuat Pelipoer Hati lebih bertahan lama.

\section{Simpulan}

Media massa atau pers merupakan alat komunikasi yang boleh dimanfaatkan oleh semua orang yang terdiri dari empat bentuk; surat kabar, majalah, tabloid, dan buletin. Melalui media massa, masyarakat bisa mengetahui berbagai informasi yang terjadi di dalam negeri maupun luar negeri. Di dalam media massa, tidak hanya memberikan berita yang ter-up to date atau terbaru namun juga memberikan informasi berupa pengetahuan umum maupun kesehatan.

Dari masa ke masa, media massa bisa dianggap sumber sejarah yang patut diperhitungkan. Kejadian atau peristiwa yang terjadi, semua dicatat pada media massa tersebut. Semua berita yang apa adanya ada di dalam media massa seperti surat kabar. Selain bisa dijadikan sumber sejarah berupa dokumen maupun arsip, surat kabar bisa dijadikan objek kajian penelitian sejarah. Di dalam surat kabar berbagai peristiwa yang sesuai dengan jiwa zamannya tentu sangat menarik untuk diteliti.

Surat kabar di Indonesia sudah ada sejak pemerintah kolonial menduduki negeri ini. Berbagai informasi dan kejadian sudah dituliskan di dalam surat kabar. Awalnya pemerintah kolonial memberikan ruang pada masyarakat pribumi dan masyarakat pendatang (asing) seperti cina (Tionghoa) untuk mendirikan surat kabar. Namun pada kenyataannya, pemerintah kolonial mengatur dan mengawasi dalam hal teknis seperti dalam penerbitan dan isi yang ada di dalam surat kabar. 
Keadaan bangsa yang masih terjajah, tentu memiliki kesulitan tersendiri bagi rakyat pribumi dalam mendirikan perusahaan penerbitan surat kabar. Selain karena sulitnya ekonomi, gerak-gerik rakyat pribumi yang selalu diawasi tentu memberikan kendala tersendiri. Bisa dikatakan, pasca politik etis, barulah banyak bermunculan berbagai macam jenis surat kabar di Indonesia. Selain karena masyarakat sudah diberikan kebebasan dalam pendidikan, masyarakat juga sudah sadar akan pentingnya tulis baca. Selain itu, sudah banyak bermunculan perusahaan penerbitan surat kabar walaupun dalam skala kecil. Hal ini tentu bisa membuktikan bahwa masyarakat sudah sadar akan terjajah dan sudah mulai menyebarluaskan informasi sebagai bentuk awal mula pergerakan di Indonesia.

Di Sumatera Barat juga tercatat memiliki perusahaan penerbitan yang cukup banyak. Namun, juga diiringi dengan singkatnya umur dari perusahaan penerbitan tersebut. Seperti yang sudah dijelaskan pada bab-bab sebelumnya, selain karena masalah ekonomi, peraturan dan undang-undang tentang pers yang dikeluarkan pemerintah kolonial juga sebagai penyebabnya. Surat kabar yang dikeluarkan tidak boleh memiliki isu-isu yang bisa merusak kekuasaan kolonial di Indonesia.

Surat kabar anak memberi tempat tersendiri dalam masyarakat terutama pelajar. POMPAl yang awalnya surat kabar ekonomi bertransformasi menjadi surat kabar anak-anak. Tidak banyak yang menulis tentang surat kabar anakanak di Sumatera Barat, sehingga penulisan tentang POMPAI ini memiliki sedikit kendala. Selain karena minimnya informasi dan data, penulisan mengenai surat kabar POMPAI secara keseluruhan pun belum pernah ada sepengetahuan penulis. Namun, penelitian ini dapat dilaksanakan dengan berbagai studi pustaka serta memakai referensi yang cukup relevan dan dengan arsip yang terbatas.

\section{Daftar Rujukan}

Dewi, S. (2014). Surat Kabar Anak Periode Kolonial :Studi tentang Eksistensi dan Pengaruh Surat Kabar terhadap Pendidikan Anak di Sumatera Barat (1930-1942). Universitas Negeri Padang.

Naldi, H. (2002). Perkembangan media pers daerah: cerminan perubahan masyarakat di sumatera barat pada masa kolonial (1900-1930). 6.

Pelipoer Hati, Edisi No. 1. (1934, November).

Surat Kabar Rantai Emas. (1931, August). 